\title{
$\beta$-Blocker prevented repeated pulmonary hypertension episodes after bilateral lung transplantation in a patient with primary pulmonary hypertension
}

Yoshinori Okada, MD, ${ }^{a}$ Yasushi Hoshikawa, MD, ${ }^{\text {a }}$ Yutaka Ejima, MD, ${ }^{\text {b }}$ Yuji Matsumura, MD, ${ }^{a}$ Tetsu Sado, MD, ${ }^{a}$ Kazuyoshi Shimada, MD, ${ }^{a}$ Hirokazu Aikawa, MD, ${ }^{a}$ Takafumi Sugawara, MD, ${ }^{\text {a } Y a s u s h i ~ M a t s u d a, ~ M D, ~}{ }^{a}$

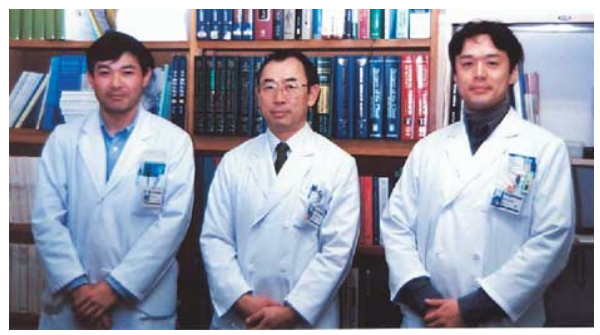

Okada, Kondo, Hoshikawa (left to right) Tohru Takahashi, MD, ${ }^{c}$ Masami Sato, MD, ${ }^{a}$ and Takashi Kondo, MD, ${ }^{a}$ Sendai, Japan

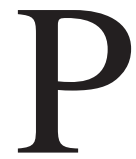
ulmonary hypertension $(\mathrm{PH})$ caused by transient left ventricular failure (LVF) is a known complication after double or bilateral lung transplantation (BLTX) for patients with end-stage $\mathrm{PH}^{1,2}$ In these patients the right ventricle (RV) becomes large and hypertrophic because of increased pulmonary vascular resistance, whereas the left ventricle (LV) becomes small and slight because of chronic preload reduction. ${ }^{3}$ Normalization of pulmonary vascular resistance by means of BLTX suddenly increases left ventricular preload, which sometimes leads to a hemodynamic situation susceptible to LVF. Prevention and treatment for this complication primarily consist of inotropic support and vasodilator therapy to reduce left ventricular afterload. $^{2}$ We present here a patient with primary PH who had repeated $\mathrm{PH}$ episodes after BLTX, for which preventative therapy composed of catecholamines and vasodilators was not effective. However, the episodes were paradoxically prevented with a $\beta$-blocker, propranolol. The clinical course and a possible mechanism responsible for the effect of the $\beta$-blocker are presented.

\section{Clinical Summary}

A 39-year-old man complained of dyspnea on exertion in 1996, and a diagnosis of primary $\mathrm{PH}$ was established by means of echocardiography and cardiac catheterization in July 1997. The patient was initially treated with oral vasodilators, but deterioration of right heart failure accompanied by massive ascites and hyperbilirubinemia required prostacyclin continuous infusion therapy in April 1999. Despite prostacyclin dose increment up to $45 \mathrm{ng} \cdot \mathrm{kg}^{-1}$

\footnotetext{
From the Department of Thoracic Surgery, Institute of Development, Aging and Cancer $^{\mathrm{a}}$; the Department of Intensive Care Medicine ${ }^{\mathrm{b}}$; and the Department of Cardiovascular Medicine, ${ }^{\mathrm{c}}$ Tohoku University School of Medicine, Sendai, Japan.

Received for publication March 4, 2004; accepted for publication March 10, 2004.

Address for reprints: Yoshinori Okada, MD, Department of Thoracic Surgery, Institute of Development, Aging and Cancer, Tohoku University, 4-1 Seiryomachi, Aoba-ku, Sendai 980-8575, Japan (E-mail: yokada@ idac.tohoku.ac.jp).

J Thorac Cardiovasc Surg 2004;128:793-4

$0022-5223 / \$ 30.00$

Copyright (C) 2004 by The American Association for Thoracic Surgery

doi:10.1016/j.jtcvs.2004.03.005
}

- $\min ^{-1}$ and concomitant inotropic support, he remained in New York Heart Association class III, and cardiac catheterization in March 2001 still showed an increased pulmonary artery pressure (PAP) of 90/35 (mean 52) mm Hg, a decreased cardiac index of $2.07 \mathrm{~L} \cdot \min ^{-1} \cdot \mathrm{m}^{-2}$, and a low blood pressure of 81/62 (mean 69) $\mathrm{mm} \mathrm{Hg}$. After 23 months of waiting, he eventually underwent BLTX from a female donor in November 2001. Surgical intervention and early postoperative course were uneventful, with a PAP of $33 / 11$ (mean 18) $\mathrm{mm} \mathrm{Hg}$ and a cardiac index of $2.94 \mathrm{~L} \cdot \mathrm{min}^{-1}$. $\mathrm{m}^{-2}$ immediately after the operation. The recipient was deeply anesthetized with sedatives and a neuromuscular relaxant during the first 48 hours in an attempt to keep his hemodynamics stable. Several hours after discontinuation of the neuromuscular relaxant on day 2 after transplantation, the first episode of PH occurred. PAP suddenly increased from a baseline of 43/15 (mean 27) $\mathrm{mm}$ $\mathrm{Hg}$ to $81 / 33$ (mean 54) $\mathrm{mm} \mathrm{Hg}$, and a chest x-ray film immediately after this episode showed pulmonary edema in both lungs. Immediate increase in the dose of sedatives and resumption of the neuromuscular relaxant gradually normalized PAP to 27/11 (mean 20) $\mathrm{mm} \mathrm{Hg}$. The duration of the PH episode was about 30 minutes. Because of the concomitant increase in pulmonary capillary wedge pressure up to $30 \mathrm{~mm} \mathrm{Hg}$ during this episode, transient LVF was postulated as the primary cause for PH. Despite inotropic support with dopamine and dobutamine, aggressive diuresis, and continuous infusion of nitroglycerin, similar transient PH episodes repeatedly occurred, with most events being triggered by means of dose reduction of sedatives or position changes. When analyzing the hemodynamic alterations in those episodes, we noted that a sudden increase of PAP and pulmonary capillary wedge pressure was accompanied by a significant increase in blood pressure and cardiac output, as shown in Figure 1. These findings made us surmise that hyperdynamic contraction of the excessively hypertrophic RV, possibly stimulated by the intrinsic catecholamine release in response to some stress to the recipient, would cause volume overload to the LV, leading to left ventricular decompensation. On the basis of this assumption, dopamine and dobutamine were discontinued by day 7 after transplantation, and intermittent injection of propranolol (approximately $1 \mathrm{mg}$ at a time) was adopted before dose reduction of sedatives or reduction in ventilatory support. After this therapeutic conversion on day 7, PH episodes became minimal and infrequent, if they occurred, and the patient was successfully extubated on day 12 after transplantation. The subse- 

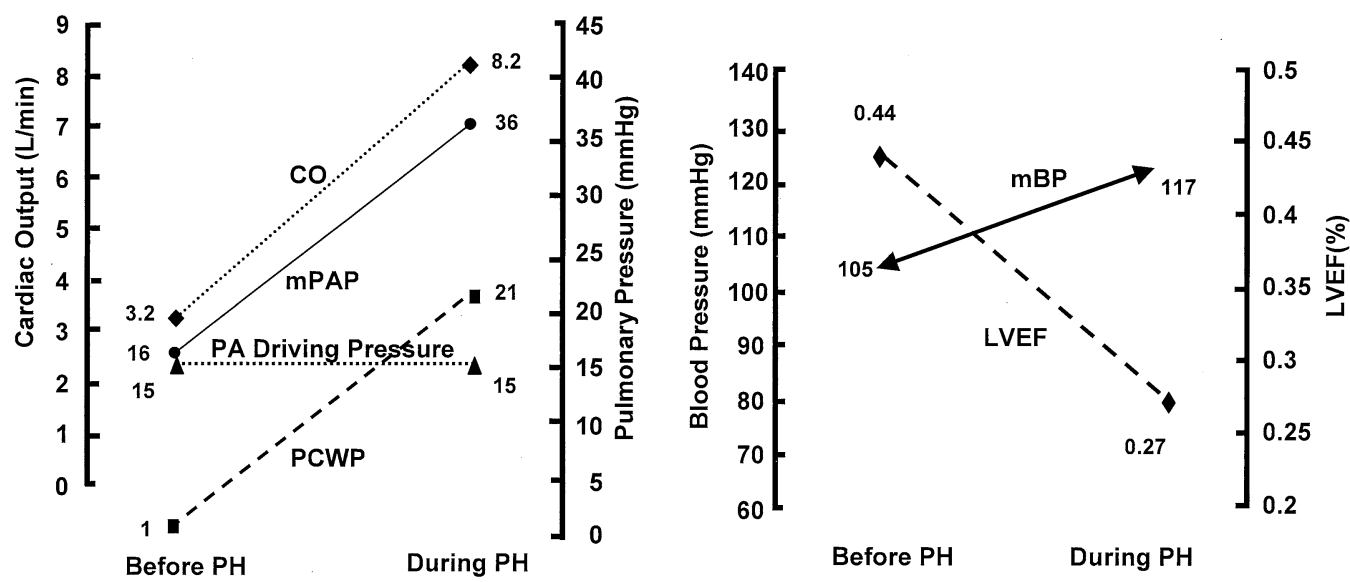

Figure 1. Hemodynamic alterations before and during a PH episode on day 5 after transplantation. $\mathrm{CO}$, Cardiac output; $m P A P$, mean pulmonary artery pressure; $P C W P$, pulmonary capillary wedge pressure; $m B P$, $\operatorname{mean}$ blood pressure; $L V E F$, left ventricular ejection fraction (measured by means of echocardiography); $P A$, pulmonary artery.

quent postoperative course was uneventful, and the patient is quite well, with no activity limitation 26 months after transplantation.

\section{Discussion}

Transient LVF after BLTX for PH has previously been described and perceived to occur on the basis of functional imbalance between the hypertrophic RV and the LV, with some dysfunction because of chronic preload reduction. ${ }^{2}$ By reviewing the hemodynamic pattern in each $\mathrm{PH}$ episode in the present case, we speculated that excessive right ventricular contraction might be the principal pathogenesis of $\mathrm{PH}$ and could be a better target for treatment rather than left ventricular dysfunction. Consequent discontinuation of catecholamines and intermittent use of propranolol dramatically prevented events of $\mathrm{PH}$ and made the subsequent weaning process uneventful. We propose a possible usefulness of $\beta$-blockers in preventing PH episodes in a carefully selected group of patients who undergo BLTX for PH, although inotropic support, aggressive diuresis, and systemic vasodilator therapy remain the mainstay of treatment for the majority of patients.

\section{References}

1. Chapelier A, Vouhe P, Macchiarini P, et al. Comparative outcome of heart-lung and lung transplantation for pulmonary hypertension. J Thorac Cardiovasc Surg. 1993;106:299-307.

2. Birsan T, Kranz A, Mares P, et al. Transient left ventricular failure following bilateral lung transplantation for pulmonary hypertension. J Heart Lung Transplant. 1999;18:304-9.

3. Xie G-Y, Lin CS, Preston HM, et al. Assessment of left ventricular diastolic function after single lung transplantation in patients with severe pulmonary hypertension. Chest. 1998;114:477-81.

\section{Authoritative}

The Journal of Thoracic and Cardiovascular Surgery is the most frequently cited thoracic/cardiovascular surgery journal in the Science Citation Index. An article in JTCVS is cited on average almost twice as often as those in the closest cardiothoracic journal. 